\title{
Does ant dispersal of seeds in Sclerolaena diacantha (Chenopodiaceae) generate local spatial genetic structure?
}

\author{
ROD PEAKALL* \& ANDREW J. BEATTIE \\ School of Biological Sciences, Macquarie University, NSW 2109, Australia.
}

\begin{abstract}
Sclerolaena diacantha is unusual in that it can exhibit contrasting diaspore dispersal at adjacent sites. At most sites, the diaspores merely, fall to the ground where secondary dispersal occurs. However, at some sites ants actively collect the diaspore that contains a food body and subsequently thousands of seeds accumulate on the long-lived ant mounds. The study evaluated the patterns of local spatial genetic structure within and among replicated sites with and without ant dispersal. Spatial autocorrelation, relatedness coefficients and gene correlation statistics based on four polymorphic allozyme loci showed that local spatial structure was minimal at two sites without ant dispersal. In contrast, moderate local spatial structure was apparent at one of the ant-dispersed sites whereas weak spatial structure was detected at the other. Restricted diaspore dispersal centred on long-lived ant mounds may explain the observed spatial structure at the first site whereas other forces appear to have contributed to the erosion of spatial structure at the second site. This multisite spatial study highlights the complexity of the interacting forces that may create or erode genetic structure in natural plant populations.
\end{abstract}

Keywords: ant dispersal, gene correlation, gene flow, genetic structure, relatedness, spatial autocorrelation.

\section{Introduction}

Theoretical models predict that plant populations will exhibit local population genetic structure when gene flow is restricted (Wright 1943; 1978). In support of these models, Turner et al. (1982) showed with computer simulations that under restricted gene flow, and in the absence of selection, a random distribution of genotypes is converted to a patchy distribution of homozygotes and heterozygotes. Subsequently, other computer studies have confirmed that positive spatial autocorrelation that declines with distance, indicating a patchy distribution of genotypes, quickly develops under restricted gene flow (Sokal \& Wartenberg 1983; Sokal et al., 1989; Epperson, 1990; Sokal \& Jacquez, 1991; Ohsawa et al., 1993). Studies of spatial structure in plant populations are important because spatial structure, when

\footnotetext{
*Correspondence: Division of Botany and Zoology, Australian
} National University, Canberra, ACT 0200, Australia. found, reflects the operation of key evolutionary processes. Furthermore, when spatial structure exists it may influence other processes such as inbreeding and microgeographical evolution.

Some empirical studies of plants where gene flow is known, or reasonably assumed, to be restricted have found local spatial genetic structure using spatial autocorrelation analysis or other related techniques (see Heywood, 1991, for review). For example, positive spatial autocorrelation at short distance classes has been detected for some allozyme loci in Gleditsia triancanthos and Maclura pomifera (Schnabel et al., 1991) and in Acer saccharum (Perry \& Knowles, 1991). On the other hand, although good estimates of pollen and seed dispersal are available for Delphinium nelsonii, spatial autocorrelation was not apparent at five allozyme loci (Waser, 1987), probably in part the result of postpollination events that bias the gene flow patterns. Similarly, spatial autocorrelation for allozyme loci has not been found in Pinus contorta (Epperson \& Allard, 1989), Picea mariana (Knowles, 1991) or Psychotria 
nervosa (Dewey \& Heywood, 1988) where it is assumed gene flow is sufficient to minimize the development of spatial genetic structure.

Epperson (1990) has identified an alternative explanation for the lack of spatial structure in some plant populations. Using computer simulations he has shown that directional selection, whereby fitness is inherent in the genotype, can greatly reduce the spatial autocorrelation normally imposed by restricted gene flow. This is a plausible explanation for the lack of spatial structure observed for a rare white floral colour mutation in Ipomoea purpurea despite strong spatial autocorrelation at another floral colour locus (Epperson, 1989, 1990). On the other hand, computer simulations by Sokal et al. (1989) reveal that selection associated with microgeographical variation can create spatial structure that is correlated with patchiness in the environment. Nevertheless, selection must be strong to offset structure caused by restricted gene flow (Sokal $e t$ al., 1989). There is some evidence that both restricted gene flow and microgeographical selection may account for the spatial structure observed at floral morphological traits in Impatiens pallida and $I$. capensis (Schoen \& Latta, 1989).

Sclerolaena diacantha is a common and widespread chenopod of arid Australia that lives from one to several years depending on seasonal conditions. The available evidence indicates that pollen flow is restricted with self-pollination accounting for up to 70 per cent of the seed set. Furthermore, although the low rate of outcrossing is probably achieved by wind-pollination, moderate genetic differentiation at several allozyme loci is apparent among sites separated by 0.1-4.1 km (Peakall et al., 1993).

The species is unusual in that it can exhibit contrasting diaspore dispersal at adjacent sites. At most sites, the woody diaspores merely fall to the ground where secondary dispersal, if any, may be effected by strong wind and/or temporary flooding during rare but occasionally very heavy rainfall. For example, we have observed that diaspores may accumulate along the edge of depressions after the local floodwaters recede. Collectively, secondary dispersal by wind and water is likely to disperse the seed randomly, although at a given time dispersal may have a strong directional component. In contrast, at sites where the ant Rhytidoponera sp. B is common, the diaspore which contains a soft food mass is actively collected by the ants that eat the food body but discard the seeds intact and viable. As a consequence, many thousands of seeds accumulate on the long-lived ant mounds and the plant is often found growing on them (Davidson \& Morton, 1981a,b; Peakall et al.,
1993). At these sites, dispersal is likely to be directional rather than random with much of the seed bank being stored in a 'safe site'. Furthermore, because the ant mounds are raised up to $1 \mathrm{~m}$ above the surrounding soil and usually vegetated, they may be an important source of seed for subsequent recolonization away from the mounds following extensive flooding.

We have predicted that seed dispersal by ants may have important genetic consequences for $S$. diacantha (Peakall et al., 1993). First, ants may assist in the creation of local genetic structure if the seed that accumulates on long-lived mounds is harvested from a restricted area year after year. Secondly, storage within the seed bank may help to retain genetic structure once it is established by enabling gene flow from the past. This temporal gene flow can reinforce spatial structure, unlike spatial gene flow which tends to homogenize it (Del Castillo, 1994). Evidence in support of these predictions has already been found. Electrophoretic analysis of seeds stored within randomly selected ant mounds at two sites revealed that genetic differentiation was three times greater among seed banks $\left(F_{\mathrm{ST}}=0.300\right)$ than among sites $\left(F_{\mathrm{ST}}=0.018\right)$ although collectively the genetic diversity stored within ant mounds was similar to the total diversity within the sites (Peakall et al., 1993). Thus in the absence of selection, it is expected that strong genetic differentiation in the seed bank will be translated into significant local spatial genetic structure in the adult population. Therefore, while seed dispersal is typically considered to be relatively unimportant as a factor influencing patterns of genetic variation in plants (Hamrick \& Godt, 1989), both pollen and seed flow are predicted to influence genetic patterns in this plant but at very different scales: within populations seed dispersal should have a strong influence whereas pollen flow is likely to be more important at the larger population scale.

In this study we take advantage of the unique opportunity afforded by the contrasting seed dispersal patterns in Scleroleana diacantha to determine whether restricted ant dispersal can generate local spatial genetic structure in the adult populations. We do this by comparing the patterns of genetic diversity and spatial structure within and among replicated sites with and without ant dispersal.

\section{Materials and methods}

\section{Study site}

Fowlers Gap Arid Zone Research Station is operated by the University of New South Wales. It is

(c) The Genetical Society of Great Britain, Heredity, 75, 351-361. 
located $112 \mathrm{~km}$ north of Broken Hill, in an arid region of Australia with an average rainfall of 200 $\mathrm{mm}$ distributed throughout the year. The vegetation is dominated by chenopods, especially saltbush (Atriplex sp.), bluebush (Maireana sp.) and shorter lived shrubs such as $S$. diacantha that reaches a maximum height of $0.3 \mathrm{~m}$.

Following a period of exceptionally good rainfall in late 1992, we returned to three of the 12 sites used in our previous study (Peakall et al., 1993). A fourth new site (S4) was also selected approximately $300 \mathrm{~m} \mathrm{NE}$ of S3. The four sites were located within an area of approximately $1.5 \times 3 \mathrm{~km}$ and full location details are given in Peakall et al. (1993). Two 'antdispersed' sites, C2 and M1, had conspicuous nest mounds of Rhytidoponera sp. B, many with $S$. diacantha growing on them. Two 'non-ant-dispersed' sites, S1 and S4, were selected because of their proximity to the ant-dispersed sites and because they did not contain nest mounds of Rhytidoponera $\mathrm{sp}$. B or other possible ant-dispersers. Hereafter, the ant-dispersed sites will be referred to as A-C2 and A-M1 while the non-ant-dispersed sites will be referred to as N-S1 and N-S4 to clearly differentiate the two types of site.

\section{Matching of the sites}

For experiments involving multiple sites, it is impossible to control for all the underlying ecological differences. In this study, we attempted to minimize major ecological differences by containing all sites in as small an area as possible (approximately $1.5 \times 3$ $\mathrm{km}$ ). All sites appeared to contain similar vegetation structures and soil type, relative to the natural range of variation within the area. Topographically, of the four sites, N-S1 was the most distinct, occurring on a flood plain close to a creek with obvious signs of past flooding. Even so, despite overall similarity, it is likely that the presence or absence of ants at the sites reflects some undetected ecological differences between sites.

At the ant-dispersed sites, ant abundance and/or plant proximity to ant mounds both appeared to be similar. The densities of active ant mounds were similar $(\mathrm{A}-\mathrm{C} 2=14, \mathrm{~A}-\mathrm{M} 1=16$ per site $)$ and the distributions of mean minimum distances between mounds were not significantly different (A-C2: $11.48 \pm 0.65 \mathrm{~m} \quad($ mean $\pm \mathrm{SD}, \quad n=14)$; A-M1: $11.53 \pm 2.09 \quad$ (mean $\pm \mathrm{SD}, \quad n=16$ ); $F_{1,28}=0.0024$, $P=0.961$ ). The median minimum distance between a plant and the nearest ant mound was $6.6 \mathrm{~m}$ at A$\mathrm{C} 2(n=165)$ and $6.0 \mathrm{~m}$ at A-M1 $(n=176)$, the 75 per cent quartile was $9.0 \mathrm{~m}$ at A-C2 and $8.0 \mathrm{~m}$ at A-
M1. Thus, approximately 75 per cent of all plants sampled at both sites fall within the range of seed dispersal (maximum of $9 \mathrm{~m}$ ) reported by Davidson \& Morton (1981a).

\section{Sample collection}

Within each of the four study sites, we sampled leaf material of $S$. diacantha at the intersects of a $3 \times 3 \mathrm{~m}$ lattice within a $30 \times 99 \mathrm{~m}$ plot. This rectangular plot size was chosen because it maximized the number of mounds that could be represented within the antdispersed sites. The $3 \mathrm{~m}$ sampling frame was chosen because it was well within the range of seed dispersal by the ants but beyond the range of maximum plant size. One consequence of this sampling strategy was that we were unable to investigate spatial structure below $3 \mathrm{~m}$. Leaf samples were stored in liquid nitrogen in the field and at $-85^{\circ} \mathrm{C}$ in the laboratory.

\section{Electrophoretic analysis}

Titan III cellulose acetate electrophoresis (Helena Laboratories, Beaumont, TX) was performed according to the procedures of Peakall et al. (1993). However, for this study we screened only the three enzyme systems that we knew to be polymorphic at the sites: menadione reductase ( $M r$, EC 1.6.99.2), glutamate oxaloaceate transaminase (Got, EC 2.6.1.1), and phosphoglucomutase (Pgm, EC 2.7.5.1).

\section{Statistical analysis of electrophoretic data}

The percentages of polymorphic loci $(P)$, gene diversities $\left(H_{\mathrm{e}}\right)$, gene correlation statistics and $\chi^{2}$-tests for Hardy-Weinberg equilibrium and differences in allele frequency were calculated using the computer program BIOSYS-1 (Swofford \& Selander, 1981). Analysis of spatial structure was performed using the approaches outlined below.

\section{Spatial autocorrelation}

An analysis of spatial autocorrelation based on the procedures of Cliff \& Ord (1981) was performed for loci polymorphic at the 95 per cent level using the computer program SAAP v4.3-A Spatial Autocorrelation Analysis Program written by D. Wartenberg (Distributed by Exeter Software, New York). For analysis the allelic data were coded as 0 when absent, 0.5 for heterozygotes and 1.0 for homozygotes. Moran's $I$ was calculated over equally spaced distance classes of $3 \mathrm{~m}$ intervals (matching the sam- 
pling frame). This coefficient is asymptotically normally distributed as $n$ increases (Cliff \& Ord, 1981). Consequently, an approximate test of significance can be made by evaluating the coefficient as a standard normal deviate. SAAP tests for significant autocorrelation based on this assumption by comparing the observed value of $I$ with the expected value $\mathrm{E}(I)=-(n-1)^{-1}$ under the null hypothesis of no spatial structure.

\section{Relatedness as a measure of spatial structure}

Recently, Nason et al. (unpublished) have introduced an alternative approach to the analysis of spatial structure based on the estimation of Wright's (1922) relatedness coefficient $\rho$ which is linearly related to Moran's $I$. The following is based on this manuscript but a brief explanation is also provided in Loiselle et al. (1995). Nason et al. have shown that the spatial relationships between the frequencies of homologous alleles, $p_{\mathrm{i}}$ and $p_{\mathrm{j}}$, in pairs of mapped individuals, $i$ and $j, \rho_{i j}$ can be estimated as:

$r_{i j}=2 \frac{\sum_{i j}\left(p_{i}-\bar{p}\right)\left(p_{j}-\bar{p}\right)}{k \bar{p}(1-\bar{p})} \quad(i<j)$,

where $p$ is the frequency of the allele with mean $\bar{p}, n$ is the number of individuals in the sample and $k=n(n-1) / 2$ is the total number of possible pairwise connections between $n$ individuals. A multilocus measure of spatial genetic structure is obtained by weighting the result for each locus by its polymorphic index, $\Sigma p_{i}\left(1-p_{i}\right)$. Values of $r_{i j}$ range from -2 to +2 with values of zero indicating that there is no spatial structure. When there is inbreeding, $r_{i j}$ will overestimate $\rho_{i j}$, but it nevertheless remains a useful statistic for describing spatial variation in population genetic structure (J. Nason et al., unpublished).

In this study, estimates of $r_{i j}$ were obtained at each site for the loci polymorphic at the 95 per cent level using a series of programs provided by J. Nason (Department of Botany, University of Georgia, Athens, USA). These programs provide single and multiple locus estimates of $r_{i j}$ adjusted for differences in sample size and they test for significance by randomly permuting the sample population. Significant spatial genetic structure is detected when the observed value for $r_{i j}$ is outside the 95 per cent confidence interval for the mean value generated by the random permutations of the data.

\section{Gene correlation}

To enable an effective comparison with our previous study, where we used $F$-statistics to investigate patterns of spatial structure, estimates of gene correlation which are related to $F$-statistics as $f=F_{1 \mathrm{~S}}$, $\theta=F_{\mathrm{ST}}$ and $F=F_{\mathrm{IT}}$ were investigated for various arrangements of subpopulations. The means and standard deviations were calculated by jackknifing across loci according to the methods of Weir \& Cockerham (1984) using an updated version of BIosys 1.7. Subpopulations with fewer than five individuals were excluded from the analysis to minimize any bias arising from small sample sizes.

\section{Results}

Plots of the sample and ant mound locations for each of the four sites are shown in Fig. 1. Approximately similar numbers of plants $(160-175)$ were

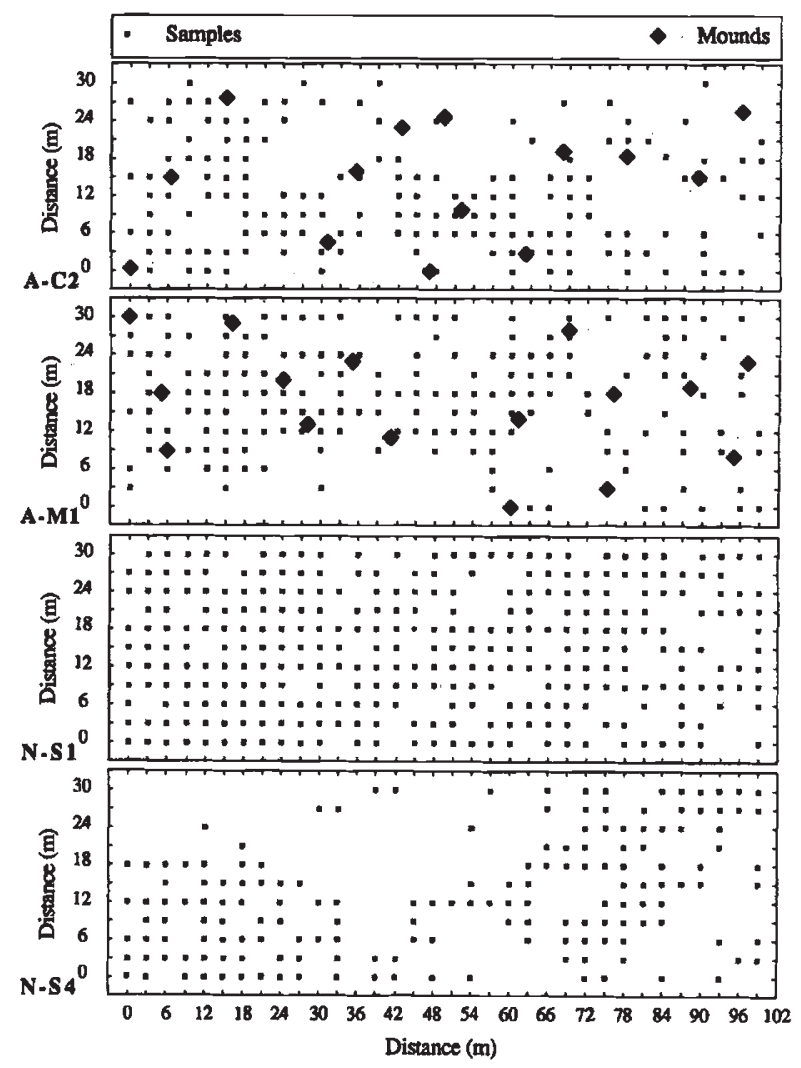

Fig. 1 Sample and mound locations within plots at the four study sites of Scerolaena diacantha. There were 14 ant mounds within $\mathrm{A}-\mathrm{C} 2$ and 16 within A-M1. The numbers of plants sampled at each site were 162, 174, 305 and 164 at A-C2, A-M1, N-S1 and N-S4, respectively. 
Table 1 Allele frequencies, mean number of alleles per locus $(A)$, mean observed heterozygosity $\left(H_{\mathrm{o}}\right)$ and mean expected heterozygosity $\left(H_{\mathrm{e}}\right)$, for the four polymorphic loci at the four study sites of Sclerolaena diacantha

\begin{tabular}{lcccc}
\hline & \multicolumn{4}{c}{ Population } \\
\cline { 2 - 5 } Locus & A-C2 & A-M1 & N-S1 & N-S4 \\
\hline Pgm & & & & \\
$n$ & 126 & 145 & 298 & 150 \\
1 & 0.298 & 0.262 & 0.799 & 0.563 \\
2 & 0.687 & 0.645 & 0.186 & 0.403 \\
3 & 0.016 & 0.093 & 0.015 & 0.033 \\
Got-1 & & & & \\
$n$ & 162 & 175 & 305 & 162 \\
1 & 0.000 & 0.000 & 0.005 & 0.012 \\
2 & 0.019 & 0.017 & 0.013 & 0.019 \\
3 & 0.975 & 0.980 & 0.931 & 0.802 \\
4 & 0.000 & 0.000 & 0.049 & 0.167 \\
5 & 0.006 & 0.003 & 0.002 & 0.000 \\
Got-2 & & & & \\
$n$ & 160 & 165 & 304 & 155 \\
1 & 0.981 & 0.691 & 0.893 & 0.961 \\
2 & 0.013 & 0.297 & 0.107 & 0.032 \\
3 & 0.000 & 0.012 & 0.000 & 0.006 \\
4 & 0.006 & 0.000 & 0.000 & 0.000 \\
$M r$ & & & & \\
$n$ & 162 & 174 & 304 & 164 \\
1 & 0.022 & 0.006 & 0.021 & 0.037 \\
2 & 0.836 & 0.974 & 0.970 & 0.841 \\
3 & 0.142 & 0.020 & 0.008 & 0.122 \\
Mean $n$ (SE) & $164.8(7.0)$ & $152.5(8.8)$ & $302.8(1.6)$ & $157.8(3.2)$ \\
$A$ (SE) & $3.0(0.0)$ & $3.0(0.0)$ & $3.3(0.6)$ & $3.3(0.3)$ \\
$H_{\mathrm{o}}$ (SE) & $0.071(0.037)$ & $0.054(0.031)$ & $0.061(0.032)$ & $0.083(0.051)$ \\
$H_{\mathrm{e}}$ (SE) & $0.259(0.124)$ & $0.202(0.098)$ & $0.177(0.057)$ & $0.300(0.092)$ \\
\hline & & & &
\end{tabular}

sampled at the three sites A-C2, A-M1 and N-S4, with almost twice as many plants sampled at site $\mathrm{N}$ S1 (305) where the species was growing more densely and uniformly.

\section{Genetic variation among sites}

Allele frequencies, sample sizes, mean numbers of alleles per locus and mean observed and expected heterozygosities are given for the four loci at each site in Table 1. Despite much larger sample sizes, only two new alleles were detected relative to our previous study: allele 5 for Got-1 and allele 4 for Got-2, but both were at only very low frequencies. Overall, allele frequencies were also similar to our previous study except that allele 1 for $\mathrm{Pgm}$ at N-S1 was more frequently represented than previously observed (see Peakall et al., 1993). Twelve or 13 alleles were observed at each site with the mean number of alleles per locus $(A)$ ranging from 3.0 to
3.3. The expected heterozygosity $\left(H_{\mathrm{e}}\right)$ ranged from 0.177 at $\mathrm{N}-\mathrm{S} 1$ to 0.300 at N-S4, indicating that $\mathrm{N}-\mathrm{S} 4$ was the most genetically diverse site.

Although most alleles were shared, there were nevertheless some significant differences in allele frequencies among the sites as shown by the moderate values of $\theta$ (Table 2). The largest degrees of genetic differentiation were found at the Pgm and Got-2 loci, but some differentiation was also apparent at the other loci. Nei's (1978) unbiased genetic distance calculated for pairwise population comparisons ranged from 0.908 to 0.976 . A UPGMA cluster analysis of these data (not shown) revealed that the populations clustered as pairs: A-C2 with A-M1 and $\mathrm{N}-\mathrm{S} 1$ with $\mathrm{N}-\mathrm{S} 4$. This is despite the geographical proximity of $\mathrm{N}-\mathrm{S} 4$ to A-C2 and A-M1, rather than to $\mathrm{N}-\mathrm{S} 1$, and may well reflect some underlying ecological difference among the sites that accounts for the presence or the absence of the ants. The results also suggest that the genetic differentiation within 
Table 2 Gene correlation statistics for Sclerolaena diacantha treating each of the four sites as subpopulations

\begin{tabular}{lccc}
\hline Locus & $f$ & $F$ & $\theta$ \\
\hline Pgm & 0.6008 & 0.6985 & 0.2448 \\
Got -1 & 0.8982 & 0.9055 & 0.0717 \\
Got -2 & 0.7769 & 0.8064 & 0.1324 \\
Mr & 0.7275 & 0.7452 & 0.0649 \\
Mean & 0.6778 & 0.7350 & 0.1984 \\
SD & 0.0863 & 0.0565 & 0.0697 \\
\hline
\end{tabular}

The means and standard deviations were calculated by jackknifing across loci according to the methods of Weir \& Cockerham (1984).

Gene correlation parameters are related to $F$-statistics as $f=F_{\mathrm{IS}}, F=F_{\mathrm{IT}}$ and $\theta=F_{\mathrm{ST}}$.

these population pairs will be lower than the average value shown in Table 2 .

Estimates for the average fixation index within sites are given by the values of $f$. Across the loci, $f$ ranged from 0.60 to 0.78 with a mean of 0.68 (Table 2 ). Because, in our earlier study, no difference in the fixation index between seedling and adult stages was observed, it is possible to estimate the relative outcrossing rate as $t=(1-F) /(1+F)$ (Jain, 1979). The results are close to our previous estimates indicating this is an inbreeding species with low levels of outcrossing in the range of 5 per cent to 25 per cent. This high level of inbreeding is probably a consequence of natural self-pollination within flowers (autogamy) and restricted wind dispersal of the pollen (Peakall et al., 1993).

\section{Spatial structure within sites-spatial autocorrelation}

Correlograms depicting the change in Moran's $I$ at equally spaced distance classes of $3 \mathrm{~m}$ intervals for alleles whose frequency exceeded 5 per cent are shown in Fig. 2. Similar patterns were observed when equal size rather than equal distance classes were used (data not shown).

Consistent positive spatial autocorrelation across loci and alleles was only observed at the A-M1 site (Fig. 2). At this site, Moran's I for the distance classes 3, 6, 9 and $12 \mathrm{~m}$ was positive but declined with distance for all Pgm and Got-2 alleles with significant departures from the expected values of Moran's $I$ at distance classes 3-9 $\mathrm{m}$. At the A-C2 site, positive and significant values of $I$ were observed for the $M r$ alleles at the distance classes $3 \mathrm{~m}$ and $6 \mathrm{~m}$ whereas values of $I$ were negative but not significant

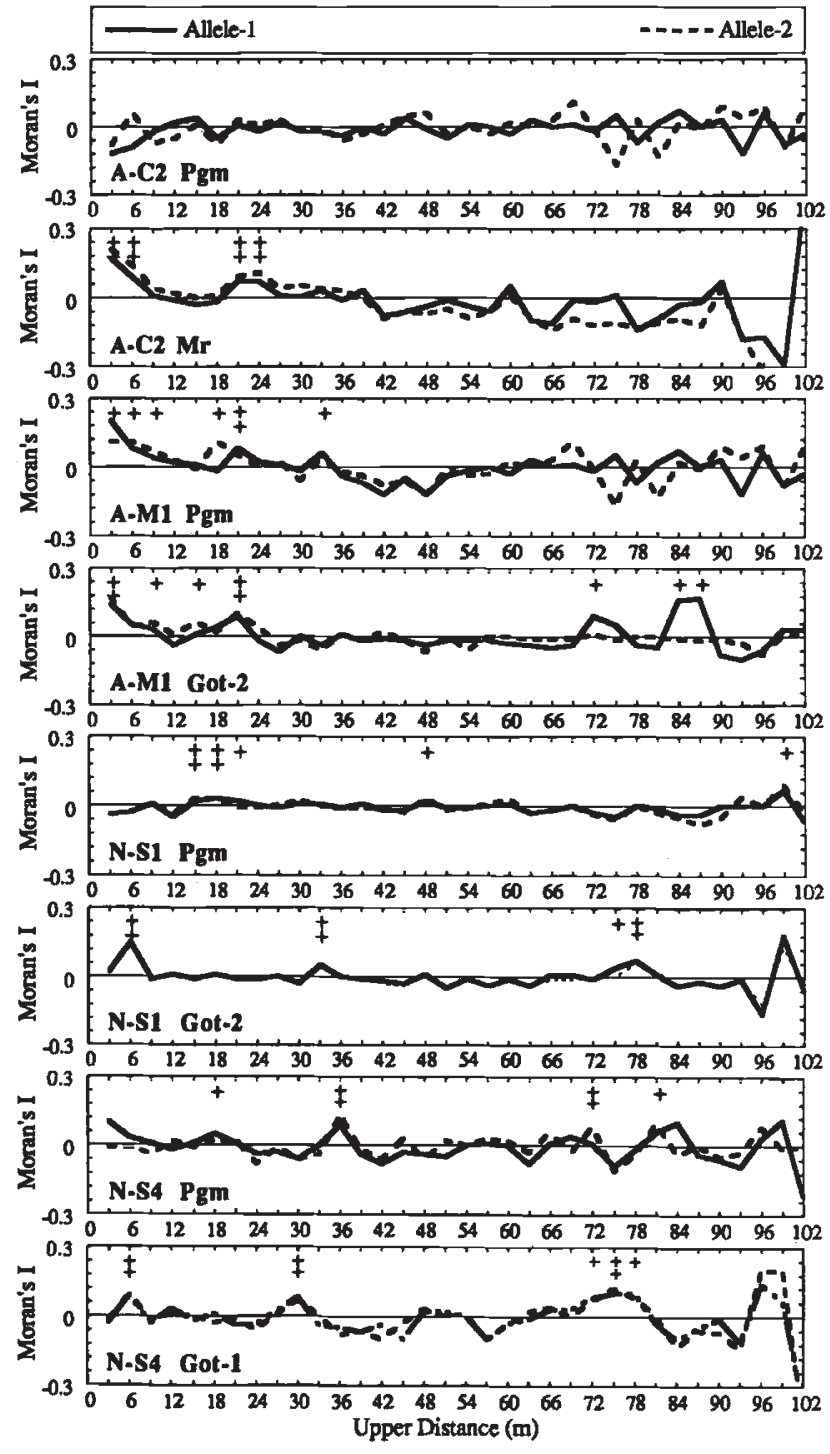

Fig. 2 Spatial autocorrelation correlograms for Moran's I for the two most polymorphic loci at each of the four sites of Sclerobena diacantha. + : significant positive autocorrelation.

for the Pgm alleles. The point at which a correlogram first crosses the $X$-axis provides an approximate estimate of patch size (Sokal \& Wartenberg, 1983). Therefore, a patch size in the range of 12-15 $\mathrm{m}$ is indicated for A-M1 with a smaller patch size of $6 \mathrm{~m}$ maximum at A-C2 (Fig. 2).

Only one significantly positive value of $I$ was observed at the first distance class at the $\mathrm{N}-\mathrm{S} 1$ site (allele 3 at $\mathrm{Mr}$ ) and none was observed at the N-S4 site. At both sites, values of Moran's $I$ for distance classes greater than $3 \mathrm{~m}$ fluctuated around zero with occasional significant negative and positive values but no consistent pattern indicating little if any spa- 
tial structure at these sites beyond the $3 \mathrm{~m}$ distance class.

\section{Spatial structure within sites - relatedness coefficient $\mathrm{r}_{i j}$}

Figure 3 depicts the changes in the relatedness coefficient $r_{i j}$ (adjusted for sample size) for equal distance classes of $3 \mathrm{~m}$ at each of the four sites and the 95 per cent confidence intervals about the mean for the null hypothesis of no spatial structure. Note that distance classes are allocated differently by the

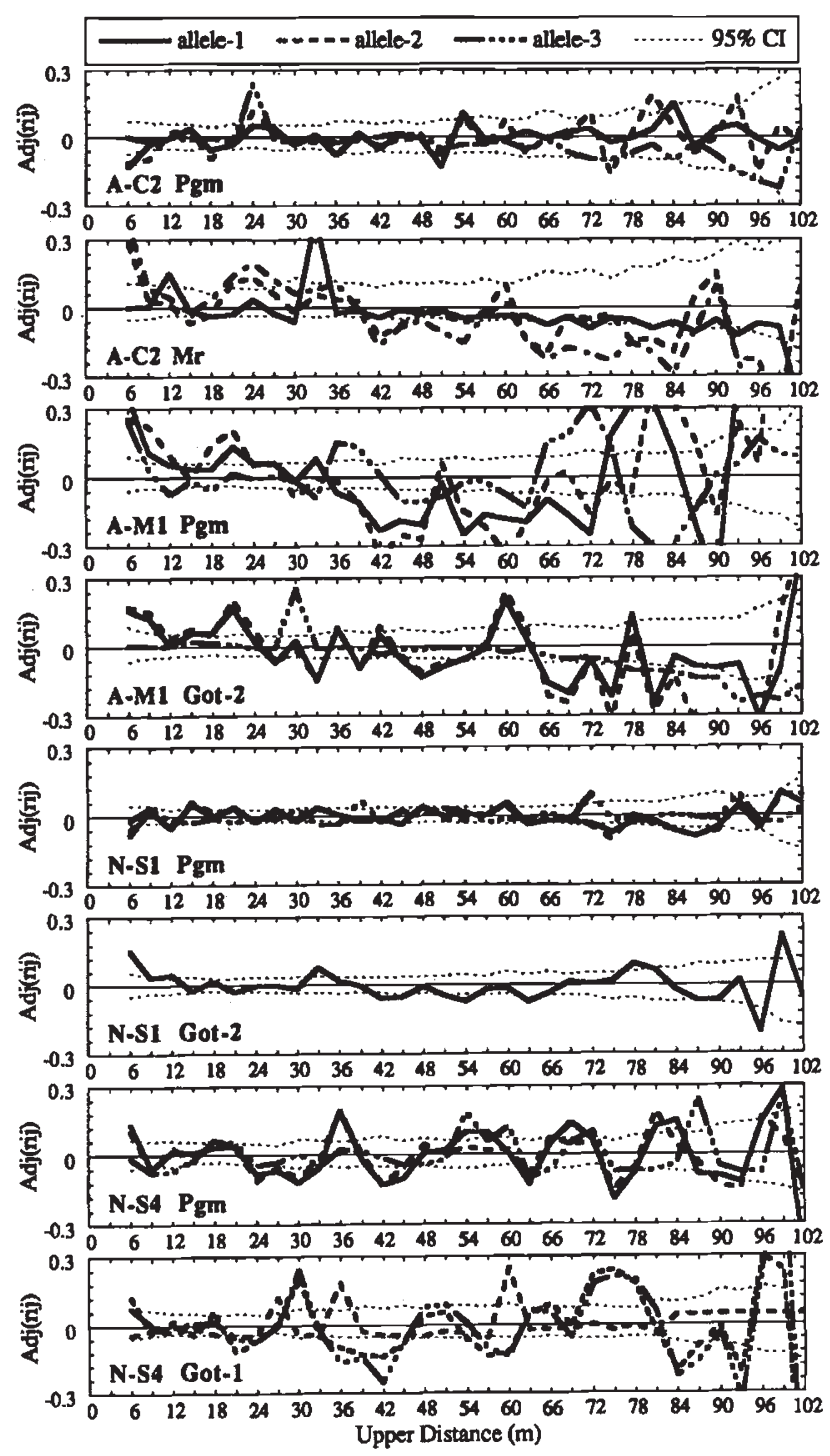

Fig. 3 Coefficients of relatedness (adjusted for sample size) as a function of distance class and 95 per cent confidence intervals for the null hypothesis of no spatial structure for the two most polymorphic loci at each of the four sites of Sclerolaena diacantha. relatedness program compared with the SAAP program, with the latter generating a meaningful $3 \mathrm{~m}$ distance in the range from 0 to and including $3 \mathrm{~m}$, whereas for the relatedness program the first meaningful distance class is $6 \mathrm{~m}$ which includes $3 \mathrm{~m}$ in its range. Some positive and significant values of $r_{i j}$ were observed at the first distance class for one or more alleles at all four sites; however, with the exception of Pgm and Got-2 at the A-M1 site, values of $r_{i j}$ mostly fall within the 95 per cent confidence intervals based on random permutation for distance classes above $6 \mathrm{~m}$ with the exception of some higher order deviations which were apparent in some cases. At A-M1, both Pgm and Got-2 alleles show a similar pattern with initial high and significant values of $r_{i j}$ which declined with increasing distance to become negative between 24 and $30 \mathrm{~m}$. Overall, the results are similar to the patterns revealed by the spatial autocorrelation analysis consistent with the expected linear relationship between Moran's $I$ and $r_{i j}$. However, the relatedness coefficient program appears to offer a more robust test of significance and better handling of missing data and small sample sizes than the SAAP program. Nevertheless, it is likely that the general conclusions will remain the same for most data sets regardless of whether SAAP or the relatedness programs are used.

\section{Spatial structure within subplots - relatedness coefficient $r_{i j}$}

To test whether the patterns of spatial structure described above hold at a smaller scale, each of the main plots within the sites was subdivided into three $30 \times 33 \mathrm{~m}$ plots. For each subplot the relatedness coefficients were calculated and plotted (data not shown). A qualitative summary of these results is shown in Table 3 for the distance class of $6 \mathrm{~m}$ (range 3-6 $\mathrm{m}$ ) for all loci and alleles. Inspection of the Table reveals notable heterogeneity of allele representation amongst subplots within sites. Similarly, patterns of spatial structure also differed among the subplots. For example, at A-M1, Pgm allele 1 was positive at all subplots and significant at two while Got-2 allele 1 was significantly positive only in the second subplot. Occasional significant positive values of $r_{i j}$ were apparent at the other three sites. Consistent with the trend detected for the plots as a whole, subplots at A-M1 were the only ones to show significant positive spatial structure at distances greater than $6 \mathrm{~m}$. The number of ant mounds found within the subplots varied from 3 to 6 , but there was no obvious relationship between mound number and $r_{i j}$ (Table 3). 


\section{Spatial structure within sites - gene correlation statistics}

The gene correlation statistic $\theta$, summarized in Table 4, revealed moderate genetic differentiation among the subpopulations centred on mounds and among random subpopulations at A-M1. However, there was little evidence for differentiation among the subpopulations centred on mounds and among random subpopulations at A-C2. Similarly, little or no genetic differentiation was apparent among random subpopulations at N-S1 and N-S4 (Table 4).

\section{Discussion}

Spatial autocorrelation, the relatedness coefficient and gene correlation statistics showed that local spatial structure was minimal at the two study sites (NS1 and N-S4) where there was no ant dispersal. In contrast, at one of the two sites (A-M1) where ant dispersal was common, local moderate to strong spatial structure was apparent relative to most other studies. Furthermore, local spatial structure was apparent across alleles for the two informative loci (Pgm and Got-2) and gene correlation analysis for all four loci also indicated genetic differentiation among subpopulations within this site. At the other ant dispersed site (A-C2), spatial structure was much weaker with only one locus $(\mathrm{Mr})$ showing local positive spatial autocorrelation. In contrast to the results at A-M1, local spatial autocorrelation was slightly negative at the Pgm locus, despite similar allele frequencies. However, spatial structure, if any, at Got-2 was probably undetectable because of the low level of polymorphism. Across all loci, genetic correlation analysis showed little genetic differentiation among subpopulations at this site.

The underlying assumption of our replicated sampling design was that the only difference between 'control' and 'treatment' is the effect of ant dispersal. Similarly, differences between replicates are assumed to be minimal. Indeed, overall the data indicate that the ant-dispersed sites were remarkably well matched for factors such as ant abundance and plant proximity to mounds that might be expected to affect the patterns and extent of diaspore dispersal by the ants. Therefore, if spatial structure was found at both ant-dispersed sites but absent in the sites without ants, it would provide support for our prediction that directed ant dispersal can generate local spatial structure. However, the findings in this study are not concordant across the ant-dispersed sites, therefore at first examination it appears that the data may not support the prediction. However, it is

Table 3 Patterns of spatial structure across alleles and loci as estimated by the coefficient of relatedness for three subplots within the major plot at each of the four sites of Sclerolaena diacantha

\begin{tabular}{|c|c|c|c|c|c|c|c|c|c|c|c|c|c|c|c|c|c|}
\hline \multirow{2}{*}{$\begin{array}{l}\text { Locus } \\
\text { Allele } \\
\text { Subplot }\end{array}$} & \multicolumn{4}{|c|}{ Pgm } & \multicolumn{4}{|c|}{ Got-1 } & \multicolumn{4}{|c|}{ Got-2 } & \multicolumn{4}{|c|}{$M r$} & \multirow[t]{2}{*}{$M$} \\
\hline & 1 & 2 & 3 & 4 & 1 & 2 & 3 & 4 & 1 & 2 & 3 & 4 & 1 & 2 & 3 & 4 & \\
\hline $\mathrm{A}-\mathrm{C} 2 / 1$ & -- & $\mathrm{a}$ & $\mathrm{a}$ & a & $\mathrm{a}$ & - & $\mathrm{a}$ & $\mathrm{a}$ & ++ & $\mathrm{a}$ & $\mathrm{a}$ & $\mathrm{a}$ & + & + & + & $\mathrm{a}$ & 3 \\
\hline $\mathrm{A}-\mathrm{C} 2 / 2$ & - & a & a & $\mathrm{a}$ & $\mathrm{a}$ & $\mathrm{a}$ & $\mathrm{m}$ & $\mathrm{a}$ & - & a & $\mathrm{a}$ & a & $\mathrm{a}$ & ++ & $\mathrm{a}$ & $\mathrm{a}$ & 6 \\
\hline $\mathrm{A}-\mathrm{C} 2 / 3$ & -- & - & - & a & $\mathbf{a}$ & $\mathrm{a}$ & $\mathrm{m}$ & $\mathrm{a}$ & $\mathrm{m}$ & a & $\mathrm{a}$ & a & $\mathrm{a}$ & ++ & $\mathrm{a}$ & $\mathrm{a}$ & 4 \\
\hline A-M1/1 & ++ & + & + & $\mathrm{a}$ & $\mathrm{a}$ & $\mathrm{a}$ & $\mathrm{m}$ & $\mathrm{a}$ & - & $\mathrm{a}$ & $\mathrm{a}$ & a & - & -- & - & $\mathbf{a}$ & 6 \\
\hline A-M1/2 & + & + & ++ & $\mathrm{a}$ & $\mathrm{a}$ & -- & $\mathrm{a}$ & $\mathrm{a}$ & ++ & a & a & $\mathrm{a}$ & $\mathrm{a}$ & + & $\mathrm{a}$ & $\mathrm{a}$ & 4 \\
\hline A-M1/3 & ++ & ++ & ++ & $\mathrm{a}$ & $a$ & - & $\mathrm{a}$ & a & -- & -- & - & a & $\mathrm{a}$ & $\mathrm{m}$ & a & $\mathrm{a}$ & 6 \\
\hline $\mathrm{N}-\mathrm{S} 1 / 1$ & - & - & - & a & $\mathrm{a}$ & - & -- & - & + & $\mathrm{a}$ & $\mathrm{a}$ & $\mathrm{a}$ & + & $\mathrm{a}$ & a & $\mathrm{a}$ & \\
\hline $\mathrm{N}-\mathrm{S} 1 / 2$ & -- & -- & - & a & + & & -- & - & + & $\mathrm{a}$ & $\mathrm{a}$ & $\mathrm{a}$ & - & $\mathrm{a}$ & $\mathrm{a}$ & $\mathrm{a}$ & \\
\hline $\mathrm{N}-\mathrm{S} 1 / 3$ & -- & -- & - & a & + & - & ++ & ++ & + & a & $\mathrm{a}$ & a & + & + & + & $\mathrm{a}$ & \\
\hline $\mathrm{N}-\mathrm{S} 4 / 1$ & + & + & -- & $\mathrm{a}$ & $\mathrm{a}$ & - & + & + & + & $\mathrm{a}$ & $\mathrm{a}$ & a & - & - & - & $\mathrm{a}$ & \\
\hline $\mathrm{N}-\mathrm{S} 4 / 2$ & - & $a$ & $\mathrm{a}$ & $\mathrm{a}$ & - & - & + & + & - & - & - & $\mathrm{a}$ & - & + & -- & $\mathrm{a}$ & \\
\hline $\mathrm{N}-\mathrm{S} 4 / 3$ & ++ & + & + & a & - & - & - & + & $\mathrm{a}$ & a & $\mathrm{a}$ & $\mathrm{a}$ & - & - & - & $a$ & \\
\hline
\end{tabular}

- : nonsignificant negative value; -- : significant negative value; $+:$ nonsignificant positive value; $++:$ significant positive value.

m: monomorphic alleles; a: absent alleles.

Qualitative results shown are based on comparisons of the estimated values of $r_{i j}$ at the 3-6 m distance class compared with the 95 per cent confidence intervals calculated by random permutation.

At the mound sites the number of mounds $(M)$ falling within each of the subplots is also shown. 
Table 4 Gene correlation statistic $\theta\left(F_{\mathrm{ST}}\right)$ for various subpopulation arrangements at each of the four sites of Sclerolaena diacantha

\begin{tabular}{|c|c|c|c|c|}
\hline Population & $\theta$ & SD & $\operatorname{Min} \theta$ & $\operatorname{Max} \theta$ \\
\hline \multicolumn{5}{|l|}{$\mathrm{A}-\mathrm{C} 2$} \\
\hline Six seed bank subpopulations $\dagger$ & 0.371 & 0.093 & & \\
\hline Subpopulations centred on mounds $\ddagger$ & 0.011 & 0.024 & & \\
\hline Mean for 10 random sets of subpopulations $\S$ & 0.005 & 0.022 & -0.020 & 0.034 \\
\hline \multicolumn{5}{|l|}{ A-M1 } \\
\hline Six seed br & 0.263 & 0.054 & & \\
\hline Subpopulations centred on mounds & 0.117 & 0.046 & & \\
\hline Mean for 10 random sets of subpopulations§ & 0.083 & 0.015 & 0.059 & 0.109 \\
\hline $\begin{array}{l}\text { N-S1 } \\
\text { Mean for } 10 \text { random sets of subpopulations§ }\end{array}$ & 0.008 & 0.005 & 0.000 & 0.016 \\
\hline $\mathrm{N}-\mathrm{S} 4$ & & & & \\
\hline Mean for 10 random sets of subpopulations $\S$ & 0.016 & 0.015 & -0.008 & 0.053 \\
\hline
\end{tabular}

†Calculated across seed bank samples taken from six randomly selected ant mounds. Based on data presented in Peakall et al. (1993). SD calculated by jackknifing across loci.

$¥$ Each subpopulation was centred on an ant mound and included all plants sampled on the lattice that were closer to the given mound than another mound. SD calculated by jackknifing across loci.

§Subpopulations were selected using a computer algorithm that first randomly allocated 15 subpopulation centres with the constraint that the centre was at least $10 \mathrm{~m}$ from another subpopulation. All plants sampled on the lattice were then allocated to the nearest subpopulation. Subpopulations with fewer than five individuals were excluded from the final analysis. Consequently, the total number of subpopulations varied among sets from 10 to 15 .

SD calculated as the standard deviation of the means across the 10 replicate sets.

clear that the differences in spatial structure between the ant-dispersed sites probably reflect factors other than ant dispersal.

\section{Possible explanations for the spatial structure differences between ant-dispersed sites}

Of the two forces most likely to generate local spatial structure, restricted gene flow is expected to affect all loci equally whereas microgeographical selection will only affect the loci under selection or those closely linked to them. Consequently, it may be possible to distinguish between the two forces if spatial autocorrelation is investigated across multiple loci (Sokal et al., 1989). Unfortunately, as there are few polymorphic allozyme loci in $S$. diacantha we lack the power to differentiate between these two forces based on the genetic data alone. Nevertheless, given a lack of obvious microgeographical variation, and the little spatial structure observed at the two sites where ants were absent, it is plausible that restricted and directed ant dispersal, recycling of seeds within long-lived ant territories and restricted pollen flow collectively contributed to the significant local spatial structure observed at A-M1. This is consistent also with the previous findings of spatial structure in the seed banks accumulated on the ant mounds (Peakall et al., 1993).

Spatial structure in the seed bank, if anything, was found to be greater at the A-C2 than for the A-M1 site (Peakall et al., 1993; Table 4) and given the well matched sites, the lack of spatial structure in the adults at A-C2 remains anomalous. More extensive interpopulation migration into the $\mathrm{A}-\mathrm{C} 2$ site than the A-M1 site may act to reduce spatial structure in $\mathrm{A}-\mathrm{C} 2$, but this would require the immigration of genes at different frequencies to those present in order to detect this effect (Sokal et al., 1989). This appears unlikely given the allele frequencies (Table 1). Similarly, directional selection which can also reduce genetic structure in the face of restricted gene flow appears an unlikely explanation. This would require differential fitness between Pgm genotypes at A-C2 but not A-M1 (spatial structure is 
probably undetectable for Got-2 at A-C2 because of the low level of polymorphism). However, similar allele frequencies were apparent for Pgm at both sites (Table 1) and the fixation indices were also similar (A-C2, $F=0.693$; A-M1, $F=0.673$ ) indicating equivalent observed and expected heterozygosities. One final, but untestable explanation for the disparity between the sites is that water-mediated secondary dispersal was sufficient at A-C2 to minimize local genetic structure. Certainly, this site did appear to exhibit more depressions where water accumulates than at the A-M1 site. The sampling period also followed a season of unusual extensive flooding. If this is the case, it would be of interest to determine if spatial structure redevelops during years when flooding is minimal.

\section{Comparisons with other multiple site studies of spatial structure}

Many of the studies employing spatial autocorrelation and related techniques to examine spatial structure have been focused on single sites (Waser, 1987; Dewey \& Heywood, 1988; Schnabel et al., 1991; Hamrick et al., 1993; etc.). As previously noted, some of these studies have found local spatial genetic structure, although in general this has been rather weak; other studies have found no local spatial structure at all. Studies of spatial structure across multiple sites may be expected to be more informative than single-site studies, especially when one can control for a variable of interest. Several mostly recent studies have examined spatial structure at multiple sites and interestingly, as in the present study, differences in spatial patterns have been found among sites. For example, Boyle et al. (1990) identified different patterns of spatial structure in Picea mariana: an upland site exhibited local spatial structure while a lowland site did not. These patterns were attributed to differences in the ecological history and mating system between the sites. Xie \& Knowles (1991) report weak spatial structure in Pinus banksiana at two of three sites. Subtle differences in the microenviroment and colonization history being probable explanations for the differences. Similarly, Knowles et al. (1992) found local spatial structure in Larix laricina at one site but not another, perhaps reflecting different recolonization processes. In a more extensive study, Young \& Merriam (1994) examined spatial structure in eight populations of Acer saccharum consisting of four 'control' populations sampled within intact forest and four 'patch' populations sampled within fragmented forest. The control populations did not exhibit positive local spatial autocorrelation although spatial patterns in one population differed from the other three. In contrast, the 'patch' populations did exhibit a local patchy structure. The authors concluded that forest fragmentation has altered genetic structure, probably as a result of changes in gene flow relative to the normal patterns in intact forest.

These studies at multiple sites highlight the complex interactions that may create or reduce local spatial structure within plant populations. In this context, it appears that the existing models for spatial structure which are mostly focused on single variables, while useful, oversimplify the true situation where the forces of migration and selection interact with even more complex factors such as ecological history.

\section{Conclusion}

In conclusion, we have argued that restricted diaspore dispersal centred on long-lived ant mounds may explain the observed pattern of local spatial structure in one ant-dispersed population of $S$. diacantha. On the other hand, it appears that despite restricted dispersal, other forces have contributed to the erosion of spatial structure in a second ant-dispersed population. Collectively, these contrasting patterns highlight the complexity of the interacting forces that create or erode genetic structure in natural populations. Our empirical observations are consistent with the conclusions of Sokal \& Wartenberg (1983) who observed on the basis of their computer studies that spatial autocorrelation and related techniques are 'not a magic key' for unlocking the secrets of population structure, but nevertheless may aid an improved understanding of the forces that generate population structure. Even so, a decade later we still have a great deal more to learn about the causes and consequences of local spatial structure in plant populations.

\section{Acknowledgments}

We thank the University of New South Wales and in particular the staff at Fowlers Gap for permission to use the Research Station. We are also grateful to John Nason (University of Georgia) who freely provided his computer programs and access to an unpublished manuscript. Craig Angus, Aletha Cruse and Ian Oliver provided technical assistance in the field and laboratory and David Gordon, Andrew Young and an anonymous reviewer commented on the manuscript. The research was funded by an Aus- 
tralian Research Council grant to A.J.B. and a Australian Postdoctoral Fellowship to R.P.

\section{References}

BOYLE, T., LieNGSiRI, C. AND PIEWLUANG, C. 1990. Genetic structure of black spruce on two contrasting sites. Heredity, 65, 393-399.

ClIFF, A. D. AND ORD, J. K. 1981. Spatial Processes. Models and applications. Pion, London.

DAVIDSON, D. W. AND MORTON, S. R. 1981a. Myrmecochory in some plants (F. Chenopodiaceae) of the Australian arid zone. Oecologia, 50, 357-366.

DAVIDSON, D. W. AND MORTON, s. R. 1981b. Competition for dispersal in ant-dispersed plants. Science, 213, 1259-1261.

DEL-CASTILLO, R. F. 1994. Factors influencing the genetic structure of Phacelia dubia, a species with a seed bank and large fluctuations in population size. Heredity, 72, 446-458.

DEWEY, S. E. AND HEYwOOD, J. s. 1988. Spatial genetic structure in a population of Psychotria nervosa. I. Distribution of genotypes. Evolution, 42, 834-838.

EPPERSON, B. K. 1989. Spatial patterns of genetic variation within plant populations. In: Brown, A. H. D., Clegg, M. T., Kahler, A. L. and Weir, B. S. (eds) Plant Population Genetics, Breeding and Genetic Resources, pp. 229-253. Sinauer Associates, Sunderland, MA.

EPPERSON, B. K. 1990. Spatial autocorrelation of genotypes under directional selection. Genetics, 124, 757-771.

EPPERSON, B. K. AND ALLARD, R. w. 1989. Spatial autocorrelation analysis of the distribution of genotypes within populations of lodgepole pine. Genetics, 121, 369-377.

EPPERSON, B. K. AND CLEGG, M. T. 1986. Spatial-autocorrelation analysis of flower color polymorphisms within substructured populations of morning glory (Ipomoea purpurea). Am. Nat., 128, 840-858.

HAMRICK, J. L. AND GODT, M. J. 1989. Allozyme diversity in plant species. In: Brown, A. H. D., Clegg, M. T., Kahler, A. L. and Weir, B. S. (eds) Plant Population Genetics, Breeding and Genetic Resources, pp. 43-63. Sinauer Associates, Sunderland, MA.

HAMRICK, J. L., MURAWSKI, D. A. AND NASON, J. D. 1993. The influence of seed dispersal mechanisms on the genetic structure of tropical tree populations. Vegetatio, 107/108, 281-298.

HEYWOOD, J. s. 1991. Spatial analysis of genetic variation in plant populations. Ann. Rev. Ecol. Syst., 22, 335-355.

JAIN, S. K. 1979. Estimation of outcrossing rates: some alternative procedures. Crop Sci., 19, 23-24.

KNOWLES, P. 1991. Spatial genetic structure within two natural stands of black spruce (Picea mariana (Mill.) B.S.P.). Silvae Genet., 40, 13-19.

KNOWLES, P., PERRY, D. J. AND FOSTER, H. A. 1992. Spatial genetic structure in two Tamarack (Larix laricina (Du Roi) K. Koch) populations with differing establisment histories. Evolution, 46, 572-576.

LOISELLE, B., SORK, v. AND NASON, J. 1995. Spatial genetic structure of a tropical understorey shrub, Psychotria officinalis (Rubiaceae). Am. J. Bot. (in press).

NEI, M. 1978. Estimation of average heterozygosity and genetic distance from a small number of individuals. Genetics, 89, 583-590.

OHSAWA, R., FURUYA, N. AND UKAI, Y. 1993. Effect of spatially restricted pollen flow on spatial genetic structure of an animal-pollinated allogamous plant population. Heredity, 71, 64-73.

PEAKAll, R., OLIVER, I., TURNBULL, C. L. AND BEATTIE, A. $J$. 1993. Genetic diversity in an ant-dispersed chenopod Sclerolaena diacantha. Aust. J. Ecol., 18, 171-179.

PERRY, D. J. AND KNOWLES, P. 1991. Spatial genetic structure within three sugar maple (Acer saccharum Marsh.) stands. Heredity, 66, 137-142.

SCHNABEL, A., LAUSHMAN, R. H. AND HAMRICK, J. L. 1991. Comparative genetic structure of two co-occurring tree species, Maclura pomifera (Moraceae) and Gleditsia triacanthos (Leguminosae). Heredity, 67, 357-364.

SCHOEN, D. J. AND LATTA, R. G. 1989. Spatial autocorrelation of genotypes in populations of Impatiens pallida and Impatiens capensis. Heredity, 63, 181-189.

SOKAL, R. R. AND JACQUEZ, G. M. 1991. Testing inferences about microevolutionary processes by means of spatial autocorrelation analysis. Evolution, 45, 152-168.

SOKAL, R. R., JACQUEZ, G. M. AND WOOTEN, M. C. 1989. Spatial autocorrelation analysis of migration and selection. Genetics, 121, 845-855.

SOKAL, R. R. AND WARTENBERG, D. E. 1983. A test of spatial autocorrelation analysis using an isolation-bydistance model. Genetics, 105, 219-237.

SWOFFORD, D. L. AND SELANDER, R. B. 1981. BIOSYS-1: a FORTRAN program for the comprehensive analysis of electrophoretic data in population genetics and systematics. J. Hered., 72, 281-283.

TURNER, M. E., STEPHENS, J. C. AND ANDERSON, w. W. 1982. Homozygosity and patch structure in plant populations as a result of nearest-neighbor pollination. Proc. Natl. Acad. Sci. U.S.A., 79, 203-207.

WASER, N. M. 1987. Spatial genetic heterogeneity in a population of the montane perennial plant Delphinium nelsonii. Heredity, 58, 249-256.

WEIR, B. S. AND COCKERHAM, C. C. 1984 . Estimating $F$ statistics for the analysis of population structure. Evolution, 38, 1358-1270.

WRIGHT, s. 1943. Isolation by distance. Genetics, 28, 114-138.

WRIGHT, s. 1978. Evolution and the Genetics of Populations, vol 4, Variability Within and Among Natural Populations University of Chicago Press, Chicago.

XIE, C. Y. AND KNOWLES, P. 1991. Spatial genetic substructure within natural populations of jack pine (Pinus banksiana). Can. J. Bot., 69, 547-551.

YOUNG, A. G. AND MERRIAM, H. G. 1994. Effects of forest fragmentation on the spatial genetic structure of Acer saccharum Marsh. (sugar maple) populations. Heredity, 72, 201-208. 